I Universidad de la República de Uruguay (UdelaR), Facultad de Ciencias Sociales, Montevidéu, Uruguai alfredofalero@gmail.com

Alfredo Falero'

\title{
A TEORIA SOCIAL DE NOVO EM MOVIMENTO
}

Domingues, José Maurício. (2018).

Emancipação e história: o retorno da teoria social.

Rio de Janeiro: Civilização Brasileira, 294p.

Sempre constitui tarefa complexa resenhar um livro sobre teoria social. Ela implica o risco, por exemplo, de simplificar excessivamente uma argumentação ou de amputar o que, para o autor, seria teoricamente decisivo. Ou ainda o de enfatiza aspectos não centrais, ou, por outro lado, o de impor as preocupações conceituais do resenhista às do autor do livro. E cabe ponderar adequadamente essa precaução porque Emancipação e história, com seu subtítulo promissor - "o retorno da teoria social" -, de José Maurício Domingues, é justamente um livro que exacerba tais riscos. Isso ocorre pela multiplicidade de janelas que abre e porque, nessas aberturas, discute e interpela a teoria social em busca de futuros.

Se se opta prioritariamente por estabelecer o denominador comum de tais aberturas, decerto cabe mencionar um eixo central, que é o dos conceitos-tendência. Naturalmente a ele se voltará pela importância que lhe confere o autor (como indica na introdução, seja de modo geral, seja com focos específicos), mas aí se deter não faria justiça a um livro que tende a importante ramificação. É que o trabalho se desenvolve na tensão permanente entre o fio condutor mencionado e as tramas conceituais tecidas a partir de discussão mais livre sobre autores e perspectivas.

Estruturado em nove capítulos, que provêm de versões anteriores publicadas em diferentes meios acadêmicos, o livro navega desde as possibilidades da teoria crítica na atualidade até as relações entre história, sociologia e modernidade, passando, entre outros pontos, pelo peronismo argentino e as deriva- 
ções conceituais que isso implica. Mas sempre se trata, ao fim e ao cabo, da discussão sobre ferramentas conceituais, de ver a teoria social em ação - de reivindicá-la como base de desenvolvimentos posteriores possíveis.

Nesse trânsito, como já adiantado, a recuperação da ideia de conceitos-tendência é central - revelando uma postura que enfrenta o desinteresse de boa parte das ciências sociais, como acertadamente aponta o autor. Pode-se dizer que se trata de buscar nessa operação a compreensão do movimento, dos processos de desenvolvimento da modernidade, de suas dinâmicas constitutivas, mas também de seus futuros possíveis - pois a ideia de movimento também pressupõe essa dimensão. Como lembrou há alguns anos o sociólogo Hugo Zemelman (I992; 20I I) (um dos maiores epistemólogos, senão o maior, que já teve a América Latina), trata-se de captar a historicidade dos processos, mas também horizontes de possibilidades.

Vários exemplos possíveis de conceitos-tendência são mencionados em distintos momentos do livro. Entre os autores "clássicos", podem ser citados os conceitos de secularização ou racionalização, em Weber, de democratização, em Tocqueville, de desenvolvimento capitalista ou mercantilização, em Marx, a discussão sobre uma nova forma de solidariedade, em Durkheim. Entre os autores contemporâneos, também há bastantes exemplos. Alguns marcados por um autor específico, como quando se fala em "sociedade em rede" - sendo, então, inevitável pensar em Castells (1998) -, outros transcen- dendo autores e perspectivas, como quando se fala em globalização.

$\mathrm{E}$, quando se entra nesse terreno, talvez nem todos os acadêmicos estejam interessados efetivamente em refletir a respeito dessa questão. Cabe chamar a atenção para este ponto: dada a tendência de redução das ciências sociais a sua instrumentalidade (Falero, 20I5a), às vezes de modo exacerbado-lembrando que esta resenha foi escrita no Uruguai, onde esse processo se deu com suas doses costumeiras de "politicamente correto" (Falero, 20I5b) -, o convite para se repensar os conceitos-tendência deve merecerum tratamento mais demorado.

Essa prevenção vale ainda mais quando o leitor enfrenta o capítulo três, sobre "questões sociais existenciais". Qualquer sociólogo que identifique conhecimento "avançado" com o sofisticado manejo estatístico fugiria espavorido diante da mera leitura do título. Nas palavras do autor, ele implica apostar em uma teorização mais flexível e inovadora e assumir que, sob a inspiração de Marx e Engels ou Weber, há temas que as coletividades humanas não podem deixar de enfrentar como espécie. Essas preocupações "existenciais" não levam necessariamente à abstração filosófica, e sim precisamente aos "conceitos-tendência”. Basta pensar, por exemplo, em "Estado moderno", com toda a projeção e entrelaçamento social que implica, bem como suas variações entre regiões do planeta, suas escalas possíveis de influência e toda a comparação possível que se desprende da operação da análise.

Isso leva a outra das preocupações que emergem do livro, que é a relação 
da sociologia com a história e a modernidade. Como se sabe, não é um tema novo.Vários sociólogos e historiadores já fizeram alguma visita à disciplina vizinha procurando encontros mais fluidos. Na sociologia, não cabem dúvidas de que os próprios autores "clássicos" encontraram na história fonte de inspiração e comparação. Como lembra Domingues, $O$ capital é um livro profundamente histórico. E em relação a Weber, ele sugere a tese de que lhe interessava mais a comparação com outras "religiões mundiais" do que a ética protestante em si.

$\mathrm{Se}$, entretanto, tivesse que escolher a partir do tema geral um plano de análise disparador de reflexões, uma escolha pertinente seria o da sociologia histórica: seu caminho realizado como especificidade dentro da sociologia e suas potencialidades de articulação com a história. Não parece claro que os pesquisadores que mergulharam nessas águas - tranquilas só na superfície - tenham saído com o auxílio de conceitos da sociologia. Pelo contrário, é plausível pensar que o tenham feito primariamente pela mão da história, marginalizando as potencialidades da sociologia, ou seja, a importância do problema está nas ferramentas conceituais que podem ser desenvolvidas para capturar processos sociais. O que foi aqui indicado de forma esquemática serve como um convite para ler o capítulo, porque agora é necessário introduzir outros tópicos.

E um deles é o do Estado moderno. Tema suficientemente amplo e complexo que - com a licença para dar uma visão própria - precisa ser resgatado dos agentes acadêmicos do mainstream que só veem instituições e criam absurdos rankings de democracia a partir daí. Em todo caso, não interessa aqui aprofundar esses assuntos. Antes, deve-se apreciar, como faz Domingues, as forças sociais operando no Estado em sua relação com o território, para colocar dois dos vários centros de sua atenção. Um sobrevoo por algumas das tradições teóricas permite tratar o Estado como - uma vez mais - "movimento" ou dinâmica, destacar conceitos que implicam essa visão processual (como o de hegemonia, de Gramsci, por exemplo) e identificar "mecanismos disruptivos ou estabilizadores" que se encontram operando contraditoriamente na realidade. Naturalmente que, aqui chegando de modo apressado, o leitor terá outra vez percebido a preocupação do autor com os conceitos-tendência.

O capítulo seis, sobre a família, é interessante porque, em primeiro lugar, o tema não ocupa geralmente o centro da atenção da teoria social, embora atualmente isso possa ter mudado com os abundantíssimos estudos feministas. Não deixa de ser um convite interessante, então, o modo como o autor tenta visualizar o peso da família na reprodução da vida social em seu conjunto. Há dois planos de análise que ele explicitamente assinala como decisivos: a questão da família dentro dos processos de modernização em nível global e o problema teórico de sua conceitualização como um dos "subsistemas" sociais.

Quanto ao primeiro plano, ao destacar que não existe uma "revolução mundial" da família, o autor entra ine- 
quivocamente em terreno comparativo. Índia e China - sociedades enormes e muito diversas em seu interior, particularmente no primeiro caso - permitem visualizar o quão arriscado é estabelecer tendências globais desconsiderando o Oriente. A ideia de um "processo de hibridização" para além da transição demográfica permite abrir - nesse caso, aprofundar - as diferentes articulações e combinações em função das classes (e das castas, na Índia), dos processos de industrialização, migrações internas, das formas de trabalho etc. Embora o caso da América Latina seja discutido com excessiva rapidez no livro, teria sido ainda mais problemático não enfrentar, nessa proposta de comparação, a região a qual se pertence - explícita ou implicitamente.

Em relação ao segundo plano, ver a família como subsistema leva a estabelecer algo básico: a família, em suas diversas formas, já não opera como um elemento central da articulação da economia, da política e do mundo religioso. Questionar essa centralidade não deve impedir considerar os arranjos familiares enquanto processos de identificação, transmissão cultural e reprodução individual ou social - questões existenciais, em suma. O ponto - cumpre lembrar que se trata de um livro de teoria social - é que se deve estar alerta diante das simplificações quanto às direções e aos ritmos da modernização. Afinal, com outras categorias, a corrente marxista também caiu em simplificações nesse sentido.

O capítulo seguinte, sobre as formas básicas de interação social, certamente levanta questões centrais para uma reconstrução da teoria social crítica. Para isso, o autor se propõe a discutir dois princípios: o da organização e o do antagonismo. As formas de trabalho pertencem ao primeiro; o conflito e a competição correspondem ao segundo. Um conjunto importante de autores é rastreado nessa distinção analítica, e desse exercício são sacadas algumas conclusões possíveis. Desta rapidíssima leitura do capítulo, complexo em algumas de suas partes, caberia resgatar um ponto: uma teoria crítica, de modo a evitar ingenuidades em suas formas de imaginar futuros sociais potenciais, não pode sugerir ou demandar que todas as relações sejam horizontais ou baseadas na colaboração voluntária.

O capítulo posterior, sobre peronismo e imaginário social, parece a priori escapar da lógica geral do livro. Basta, porém, transitar por ele para se constatarque também aíemergem questões de fundo que atravessam a publicação. Em termos principais, pode-se dizer que a ideia política do peronismo - tão inacessível e fugidia para quem não vive na Argentina-representa precisamenteem sua constituição e reprodução um "magma de significações flutuantes" - e, portanto, comporta inflexões simbólicas nessa variável amálgama de interesses. $\mathrm{E}$, tal como acontece com a noção mais geral e latino-americana de populismo, seu usoimplica toda sorte de mal-entendidos e inumeráveis debates políticos e acadêmicos. De modo que, deslindando seu status de conceito ou categoria de análise, é melhor deixar o tema simplesmente ao que o autor diz sobre o assunto. 
O capítulo final, sobre teoria social crítica, pode ser visto como um balanço das ciências sociais em alguns de seus aspectos - especialmente quanto a suas promessas e realizações. É também uma aposta na reconstrução, na revalorização do conhecimento que emerge desse campo de conhecimento e, sobretudo, no papel da teoria crítica (em um sentido não restrito aos aportes da Escola de Frankfurt). Entre as alternativas teóricas integradas a modo de sobrevoo - aprofundar essa integração constituiria um livro em si mesmo -, aparecem Boaventura de Sousa Santos e Antonio Negri. Sem dúvidas, dois teóricos contemporâneos incontornáveis, para além de seus acordos e divergências. Buscar na realidade atual as tendências de desenvolvimento de transformações sociais e promover uma renovação da teoria crítica a partir de uma agenda de pesquisa - eis uma aposta necessária, da qual os conceitos-tendência devem ser parte central, do mesmo modo que foram nas teorias sociais da modernidade, tal como demonstra Domingues.
Dois elementos finais cabem como balanço geral. Em primeiro lugar, muitas das preocupações aqui expostas - a modernidade contemporânea e o lugar do Brasil e da América Latina ou da teoria crítica em geral - já formam parte, sem sombra de dúvidas, da trajetória do autor. Nesse livro, reafirma-se que, em vez de pensar múltiplas modernidades, é preferível partir da ideia de uma modernidade global, porém heterogênea. Nesse sentido, embora não se encontre aí novidade, tampouco essas questões suscitarão, para quem já tenha transitado pela produção de José Maurício Domingues, a sensação de reiteração. Em segundo lugar, apesar da abertura de temas e reflexões diversas, cabe ponderar que o produto final ostenta razoável integração. Quer dizer, a despeito de algumas rupturas entre os capítulos, as discussões teóricas vão colocando insumos para um mesmo caminho analítico. Sem ilusões mistificadoras, mas também sem mera acumulação de desalentos e frustrações, apenas cabe a necessidade da persistência que subjaz ao trabalho.

Recebida em I $4 / 4 / 2018$ Aprovada em 28/4/2018

\footnotetext{
Alfredo Falero é doutor em ciências sociais com especialização em sociologia, professor da graduação e da pós-graduação, bem como pesquisador, do Departamento de Sociologia da Faculdade de Ciências Sociais da Universidad de la República (Uruguai) e cocoordenador do GT de Clacso Intelectuales y Política. A mais recente de suas numerosas publicações é "El nuevo sentido común emprendedor y las batallas por las subjetividades colectivas".
} 
698

\section{REFERÊNCIAS BIBLIOGRÁFICAS}

Castells, Manuel. (1998). La era de la información, 3 tomos. Madrid: Alianza Editorial.

Falero, Alfredo.(20i5a). Problemas contemporáneos en la proyección de la teoría social y algunos desafíos inmediatos. Trabajo presentado al I Congreso Latinoamericano de Teoría Social, Buenos Aires, 20I5. In: Teoría social desde América Latina. Las posibilidades críticas de los abordajes clásicos, contemporáneos y emergentes. Buenos Aires, no prelo.

Falero, Alfredo. (2015b). De amnesias conceptuales e intelectos capturados. Algunos aportes de la década del sesenta para pensar América Latina en el siglo XXI. In: Acosta, Ansaldi et al. América Latina piensa América Latina. Buenos Aires: Clacso.

Zemelman, Hugo. (20I I). Los horizontes de la razón, tomo III. Barcelona: Editorial Anthropos/Centro de Estudios en Conocimiento y Cultura en America Latina de la Universidad de Manizales (Colombia).

Zemelman, Hugo. (I992). Los horizontes de la razón, tomos I y II. Barcelona: Editorial Anthropos/El Colegio de México. 